University of Nebraska - Lincoln

DigitalCommons@University of Nebraska - Lincoln

2014

\title{
The Impact of Interface Design During an Initial High-Technology AAC Experience: A Collective Case Study of People with Aphasia
}

\author{
Aimee R. Dietz \\ University of Cincinnati, aimee.dietz@uc.edu \\ Kristy S.E. Weissling \\ University of Nebraska - Lincoln, kristy.weissling@unl.edu \\ Julie Griffith \\ University of Cincinnati, julie.griffith@uc.edu \\ Miechelle L. McKelvey \\ University of Nebraska-Kearney, mckelveyml@unk.edu \\ Devan Macke \\ University of Cincinnati
}

Follow this and additional works at: https://digitalcommons.unl.edu/specedfacpub

Part of the Other Analytical, Diagnostic and Therapeutic Techniques and Equipment Commons, Special Education and Teaching Commons, Speech and Hearing Science Commons, and the Speech Pathology and Audiology Commons

Dietz, Aimee R.; Weissling, Kristy S.E.; Griffith, Julie; McKelvey, Miechelle L.; and Macke, Devan, "The Impact of Interface Design During an Initial High-Technology AAC Experience: A Collective Case Study of People with Aphasia" (2014). Special Education and Communication Disorders Faculty Publications. 152. https://digitalcommons.unl.edu/specedfacpub/152

This Article is brought to you for free and open access by the Department of Special Education and Communication Disorders at DigitalCommons@University of Nebraska - Lincoln. It has been accepted for inclusion in Special Education and Communication Disorders Faculty Publications by an authorized administrator of DigitalCommons@University of Nebraska - Lincoln. 


\title{
The Impact of Interface Design During an Initial High-Technology AAC Experience: A Collective Case Study of People with Aphasia
}

\author{
Aimee Dietz, ${ }^{1}$ Kristy Weissling, ${ }^{2}$ Julie Griffith, ${ }^{1}$ Miechelle McKelvey, ${ }^{3}$ and Devan Macke ${ }^{1}$
}

\begin{abstract}
1 Department of Communication Sciences and Disorders, University of Cincinnati, Cincinnati, $\mathrm{OH}$
2 Department of Special Education and Communication Disorders, University of Nebraska-Lincoln, Lincoln, Nebraska

3 Department of Communication Disorders, University of Nebraska-Kearney, Kearney, Nebraska

Corresponding author - Aimee Dietz, University of Cincinnati, Department of Communication Sciences \& Disorders, 3202 Eden Avenue, Cincinnati, OH 45267- 0379, USA; tel 513-558-8551, email aimee.dietz@uc.edu
\end{abstract}

\begin{abstract}
The purpose of this collective case study was to describe the communication behaviors of five people with chronic aphasia when they retold personal narratives to an unfamiliar communication partner using four variants of a visual scene display (VSD) interface. The results revealed that spoken language comprised roughly $70 \%$ of expressive modality units; variable patterns of use for other modalities emerged. Although inconsistent across participants, several people with aphasia experienced no trouble sources during the retells using VSDs with personally relevant photographs and text boxes. Overall, participants perceived the personally relevant photographs and the text as helpful during the retells. These patterns may serve as a springboard for future experimental investigations regarding how interface design influences the communicative and linguistic performance of people with aphasia.
\end{abstract}

Keywords: Aphasia, Augmentative and alternative communication, AAC, Visual scene displays, VSDs, Personally relevant materials, Text, Assessment

\section{Introduction}

The recent mobile technology boom has generated devices that are lightweight, readily available, and socially desirable. These devices, along with the advent of relatively inexpensive communication applications ("apps"), have created an opportunity to facilitate the integration of augmentative and alternative communication (AAC) into the aphasia rehabilitation process. In fact, people with communication disorders, including people with aphasia, are embracing these technological advances because of increased social acceptance of AAC (McNaughton \& Light, 2013) and often seek assistance from speech language pathologists (SLPs) to integrate these tools into their communication repertoire (AAC-RERC, 2011; Dietz, Quach, Lund, $\&$ McKelvey, 2012). However, SLPs may find themselves overwhelmed by the vast array of downloadable communication apps and their various interface features. For this reason, it is imperative to generate evidence regarding the impact of AAC interface features on the communicative and linguistic performance of people with aphasia. As we continue into the 21st century, the ever-increasing availability of mobile technology and onslaught of communication apps makes integrating AAC into the rehabilitation process particularly pressing.

\section{Visual Scenes Displays for People with Aphasia}

Visual scenes displays (VSDs) are one interface option for people with aphasia. As described in the aphasia and AAC literature, VSDs typically employ personally relevant photographs and related text, as well as speech output on high-tech devices (Dietz, McKelvey, \& Beukelman, 2006). Furthermore, VSDs for people with aphasia typically use an autobiographical organizational strategy, in which information is situated according to the personal account of the person with aphasia. Proponents hypothesize that VSDs minimize the linguistic and working memory demands of traditional grid layouts by facilitating gestalt comprehension of the content (Dietz et al., 2006; Wilkinson \& Jagaroo, 2004; Wilkinson, Light, \& Drager, 2012) as well as access to episodic stores. Figure 1 compares and contrasts a VSD and traditional grid layout. 


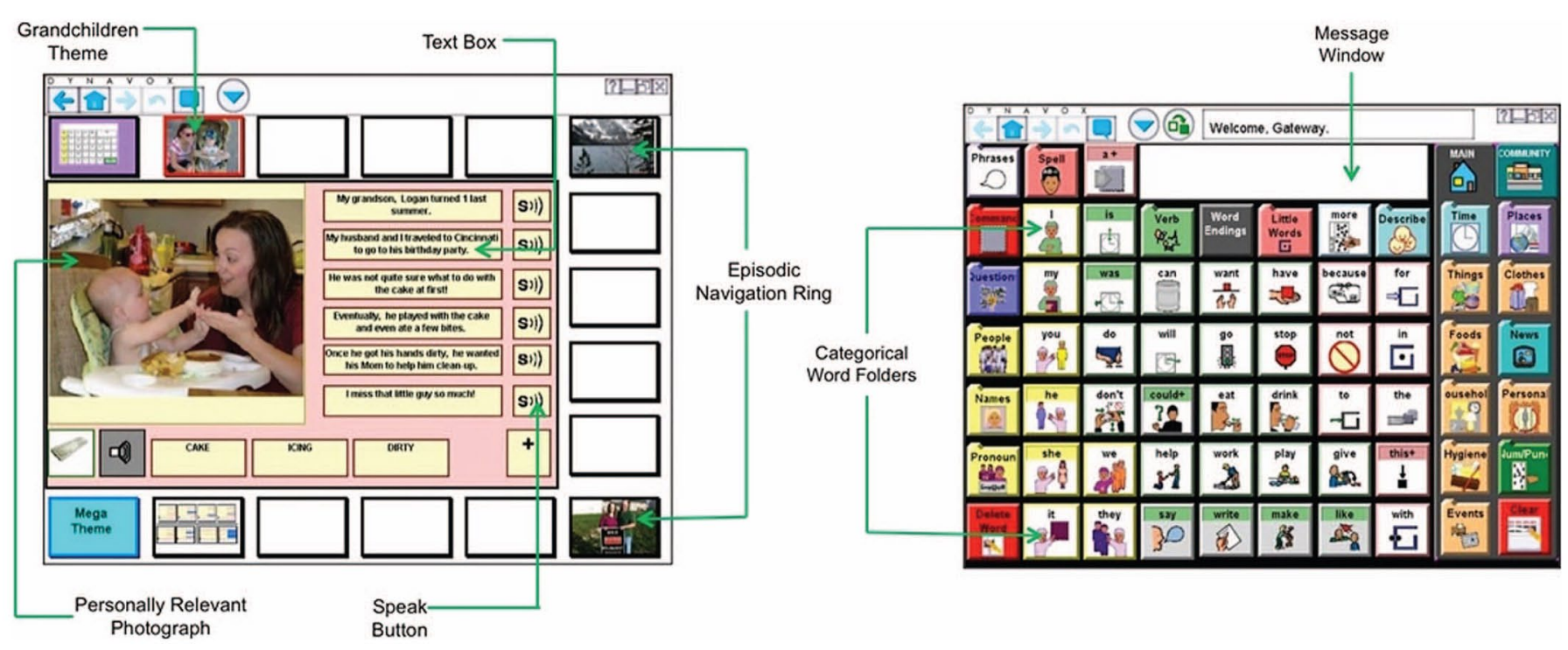

Figure 1. A comparison of a VSD and traditional grid layout. @ 2014 DynaVox Mayer-Johnson. All rights reserved.

The notion of reducing the linguistic and working memory demands of AAC interfaces for people with aphasia is critical given that the fundamental use of AAC for people with aphasia is due to their underlying linguistic impairment (e.g., Garrett \& Lasker, 2013) and associated working memory challenges (e.g., Wright, Downey, Gravier, Love, \& Shapiro, 2007). Recent evidence suggests that people without disabilities rely on phonological encoding, a form of working memory, to recall word lists using a semantic-organization strategy on an AAC system (Dukhovny \& Soto, 2013). More evidence is needed to understand whether people who use AAC demonstrate this same tendency. Because, prior to their stroke, people with aphasia communicated using natural language, it is logical to consider that they may also employ phonological encoding - or at least attempt to phonologically encode - during AAC learning. Therefore, the use of an unfamiliar symbol system may slow down the ability of people with aphasia to successfully learn grid-based symbol systems. Beyond the word level, it is also known that working memory is required to compose a syntactically correct message using an AAC system (Thistle \& Wilkinson, 2013; Wilkinson \& Jagaroo, 2004; Wilkinson et al., 2012). To complete this task, a person must keep in mind the target message (in working memory) while navigating the AAC system to locate the target symbol. Since the autobiographical memory of people with aphasia is typically thought to be relatively well preserved, personalized VSDs may reduce the demands on working memory, as the target symbols do not need to be committed to long-term memory. Instead, the photographic representations are of the users' life experiences. Based on these ideas, an emergent body of evidence suggests that VSDs facilitate improved communicative success (Dietz et al., 2006; Dietz, McKelvey, Schmerbach, Weissling, \& Hux, 2011; Hux, Buechter, Wallace, \& Weissling, 2010; McKelvey, Dietz, Hux, Weissling, \& Beukelman, 2007) as well as relatively efficient learning of system navigation (McKelvey et al., 2007; Wallace \& Hux, 2013). As alluded to previously, a key element to the success of VSDs appears to be the personalized interface.

Personally Relevant Materials. Early reports in aphasiology provided anecdotal data that people with aphasia demonstrate improved linguistic performance within the context of personally relevant materials (Schuell, 1953). Subsequent studies provided additional evidence that, when personally relevant materials are employed, people with aphasia demonstrate improved auditory comprehension, speech repetition, naming, reading comprehension, and word-picture matching accuracy (McKelvey, Hux, Dietz, \& Beukelman, 2010; Jones, Pierce, Mahoney, \& Smeach, 2007; Wallace \& Canter, 1985). Furthermore, people with aphasia express a preference for the use of personally relevant stimuli (McKelvey et al., 2010). Recent evidence from computer learning (i.e., on-line learning modules) suggests that people may become easily frustrated, disoriented, or have a difficult time interacting with systems that include unfamiliar information (Chen, Fan, \& Macredie, 2006). It is not known whether this also occurs when people with aphasia are asked to use AAC interfaces with non-personally relevant photographs.

Baddeley's revised model of working memory (2000) may explain why people with aphasia perform at higher linguistic and communicative levels when using personally relevant materials. This model includes three systems of temporary information storage; the phonological loop (auditory speech information), the visual spatial sketchpad (visual information), and the episodic buffer (which interacts with long-term episodic memory). The fourth element of this model, the central executive, is responsible for determining how cognitive resources should be allocated to tasks. Together, the phonological loop, visual spatial sketchpad, and the episodic buffer work to provide the central executive the information necessary to best determine 
how to manage the task at hand (Baddeley, 2000). If all three of these systems are adequately activated by stimuli, or if one system can be activated more strongly, there may be a greater chance of activation of long-term episodic memory. Thus, compared to non-personally relevant VSDs, personalized VSDs may more strongly activate long-term episodic memory through the visual sketchpad. For instance, during incidents of word retrieval challenges and/ or in cases of more severe aphasia, in which the language system cannot be adequately stimulated for verbal production, the intact visual spatial sketchpad may be called upon for greater input during a given task. Thought to be housed in the spared right hemisphere of the brain, the visual spatial sketchpad may convey information to the central executive and thereby assist in the selection of the best strategy for successful communication (e.g., pointing to elements on an AAC interface such as a picture, word, etc.) during an anomic event. Although non-personally relevant photographs are likely to activate the visual spatial sketchpad, the activation is probably less intense than if both the visual spatial sketchpad and the episodic buffer are activated. This may result in reduced activation of long-term episodic memory. Therefore, the ability of the central executive to properly allocate resources to the language/communication task may be reduced in the presence of non-personally relevant materials compared to personally relevant pictures.

Presence of Text. In addition to the use of personally relevant materials, the presence of text on VSDs may play an important role in facilitating improved communication for people with aphasia. Early reports on the implementation of VSDs indicated that people with aphasia - despite their moderately to severely impaired reading comprehension challenges - were reluctant to use speak buttons unless text boxes were present (Dietz et al., 2006). There are several instances in the literature that document the effectiveness of using text to facilitate improved communicative or linguistic performance. For example, Garrett and Huth (2002) examined the individual and combined impact of text and photographs on the communication behaviors of people with aphasia. Results revealed significant differences in the quality and quantity of communicative interactions in the presence of photographs and text. Wambaugh and Wright (2007) reported on a person with moderatesevere Wernicke's aphasia, who demonstrated improved naming during a word retrieval intervention that included written word forms paired with pictures. This is similar to the AAC strategy of using a letter board or word dictionary to facilitate communication of ideas during anomic events (Garrett, Beukelman, \& Low-Morrow, 1989).

The written choice strategy (Garrett \& Beukelman, 1995) is another example of how text can be used to facilitate improved auditory comprehension and expression of ideas for people with aphasia. For example, if a person with aphasia cannot verbalize his or her place of birth, a communication partner can write down the question, "Where are you from?" and then provide possible options, also in writing: Ohio, Kentucky, Indiana, or other. This allows the person with aphasia to point to or speak the target response; some research suggests that people with severe aphasia and reading comprehension challenges can successfully use this technique (Smith \& Garrett, 2005). In these examples, the text was paired with personally relevant photographs and/or topics, which likely activated long-term episodic memory.

Since the first case study on AAC in aphasia emerged (Garrett et al., 1989), a plethora of AAC interface options have materialized. Recent literature suggests that, due to the inclusion of personally relevant materials, high-technology VSDs offer people with aphasia the opportunity to use AAC systems that build on their relatively preserved autobiographical memory to communicate (Dietz et al., 2006; 2011; Hux et al., 2010; McKelvey et al., 2007). However, the varying effects of personally relevant and nonpersonally relevant materials, as well as the presence of text on the communication behaviors of people with aphasia have not been described. Even more, clinicians often make AAC recommendations using data from limited device/ interface trial sessions. As such, information is needed regarding how people with aphasia respond during an initial high-technology AAC experience. Therefore, we used a collective case study of five adults with chronic aphasia to describe their communicative behaviors and interface preferences when they retold four personal narratives to a naïve communication partner using four variants of a VSD interface. The four interfaces were: (a) personally relevant photographs with text boxes (PR[+]), (b) personally relevant photographs without text boxes (PR[-]), (c) nonpersonally relevant photographs with text boxes (NPR $[+])$, and (d) non-personally relevant photographs without text boxes (NPR[-]). The following questions were asked:

(1) What available modalities did the people with aphasia use during the narrative retells?

(2) What patterns of communication breakdowns and repairs emerged during the narrative retells?

(3) What was the impact of non-personally relevant photographs on off-topic talk time and communication breakdowns during the retells?

(4) What elements of the VSD interface did the participants perceive as helpful?

(5) What elements of the interface did the communication partner perceive as helpful?

\section{Method}

\section{Participants}

The study included one communication partner and five people with aphasia. The communication partner was a 21-year-old female undergraduate student in speech 
language pathology, who was blind to the purpose of the study and had no prior experience with AAC or interacting with people with aphasia. The five participants with chronic aphasia had all experienced a single left cerebrovascular accident (CVA) $(M=144$ months post-onset; range: 36-252 months). Four people displayed moderate nonfluent aphasia (i.e., three Broca's and one transcortical motor) and one person presented with fluent aphasia (i.e., transcortical sensory), as determined through their performance on the Western Aphasia Battery-Revised (WAB-R) (Kertesz, 2006). Administration of the Reading Comprehension Battery for Aphasia-2 (La Pointe \& Horner, 1998) revealed that four of the five participants had relatively mild reading and auditory comprehension challenges, while one (Randy) exhibited moderately impaired comprehension challenges. All participants were right-handed; were medically stable; had a negative history of major psychotic episodes or intractable substance abuse; had at least a high school education; and were native speakers of American English. Lastly, all passed hearing and vision screenings, indicating sufficient hearing and vision to perform the study tasks. Table 1 provides a summary of the participants' demographic information; the following sections provide a brief summary of each participant's medical, social, educational, and vocational history.

Brian. Brian was a 40-year-old male who displayed Broca's aphasia (WAB-R AQ = 63.3) with concomitant, moderate apraxia of speech; he was 21 months post-stroke at the time of the study. He had a Bachelor's degree and, due to the stroke, had retired from a career in information technology. Brian received speech-language therapy after his CVA and communicated primarily through halting spoken expression with perseverative utterances. He also used a PalmTop ${ }^{\mathrm{TM}}$, along with text-to-speech features on a laptop, which he frequently carried with him to communicate and repair breakdowns. Brian did not have children and lived with his wife at the time of the study.

Randy. Randy was a 55-year-old male who exhibited transcortical sensory aphasia (WAB-R AQ $=60.7$ ) secondary to a CVA 23 months prior to the study. Randy had a Master's degree and prior to his stroke was the chief executive officer of a local company. Following his stroke,
Randy received extensive aphasia rehabilitation; however, he was unable to return to work due to his communication challenges. He communicated primarily through fragmented spoken and written expression, often using gestures and drawings to repair communication breakdowns and anomic events. At the time of the study, Randy was not married but maintained close relationships with several members of his immediate family.

Kelly. Kelly was a 65-year-old female was more than 120 months post-stroke and exhibited Broca's aphasia (WAB-R $\mathrm{AQ}=52.1$ ) with concomitant, moderate-severe apraxia of speech. She had a Bachelor's degree and was a retired elementary school educator. Kelly received extensive poststroke language rehabilitation and her communication consisted of 1-2 word phrases of halting speech, which she supplemented with gestures. She also used a PalmTop to augment her communication; however, her family reported and the first author observed that she experienced challenges successfully navigating the system during interactions. Kelly was a wife, mother, and grandmother at the time of the study.

Phil. Phil was a 57-year-old male who was 36 months post-stroke and displayed transcortical motor aphasia (WAB-R AQ = 72.4). He had a Bachelor's degree in engineering and, following his CVA, retired from a local company as the chief executive officer. Phil received speech and language services after his stroke but had no previous experience with an AAC device. He had no evidence of a concomitant motor speech disorder and communicated primarily through the use of natural speech, which was characterized by anomic events and breakdowns that he resolved with writing. At the time of the study, Phil was a husband and father of two young children.

Anne. Anne was a 72-year-old female who was 252 months post-stroke at the time of the study. She exhibited moderate Broca's aphasia (WAB-R AQ $=61.1$ ) and concomitant, moderate apraxia of speech. Anne's education included some college. Following her stroke, she communicated in short phrases and exhibited frequent phonemic paraphasias. She received aphasia rehabilitation previously; although she was aware of AAC technology,

Table 1. Demographic and Language Measures.

\begin{tabular}{|c|c|c|c|c|c|c|c|c|c|c|}
\hline Participant & Age & Gender & $\begin{array}{l}\text { Education } \\
\text { level }\end{array}$ & Ethnicity & $\begin{array}{l}\text { Months } \\
\text { post-onset }\end{array}$ & $\begin{array}{c}\text { High-tech AAC } \\
\text { experience }\end{array}$ & $\begin{array}{c}\text { WAB-R } \\
\text { AQ }^{a}\end{array}$ & $\begin{array}{l}\text { Aphasia } \\
\text { type }\end{array}$ & $\begin{array}{l}\text { WAB-R } \\
\text { aud comp }\end{array}$ & $\begin{array}{l}\text { RCBA-2 } \\
\text { total score }\end{array}$ \\
\hline Brian & 40 & Male & Bachelor's & Caucasian & 21 & Yes & 63.3 & Broca's ${ }^{\mathrm{e}}$ & 181 & 84 \\
\hline Randy & 55 & Male & Master's & Caucasian & 23 & No & 60.7 & $\mathrm{TCS}^{\mathrm{d}}$ & 127 & 67 \\
\hline Phil & 57 & Male & Bachelor's & Caucasian & 36 & No & 72.4 & $\mathrm{TCM}^{\mathrm{f}}$ & 184 & 92 \\
\hline Anne & 72 & Female & Some College & Caucasian & 252 & No & 61.1 & Broca's ${ }^{\mathrm{e}}$ & 139 & 81 \\
\hline
\end{tabular}

a) WAB-R AQ = Western Aphasia Battery-Aphasia Quotient, maximum score = 100; b) WAB-R auditory comprehension total raw score, maximum $=200 ; \mathrm{c}$ ) RCBA-2 = Reading Comprehension Battery for Aphasia, maximum score = 100; d) TCS = Transcortical Sensory; e) Apraxia of speech present; f) Transcortical Motor. 
she reported no AAC usage prior to this investigation. Anne was a retired office manager, wife, mother, and grandmother.

\section{Materials}

Equipment and Software. The researchers created the VSD displays on the DynaVox VMax ${ }^{\mathrm{TM}} .{ }^{2}$ All narrative retell sessions were videotaped using three digital video camera recorders (Canon FS200 ${ }^{3}$ ). One camera focused on the faces and upper bodies of the participants to capture their facial expressions and gestures. The second camera focused on the screen of the DynaVox VMax, which displayed the programmed narratives. The third camera was focused on a pad of paper located in front of the person with aphasia, to record content conveyed through written or drawn modalities.

Narrative Stimuli. The participants co-constructed with a researcher, eight personal narratives using the procedures outlined by Dietz et al. (2006). Briefly, the participants brought in eight narrative topics, drafted out (at least in part) by a caregiver, and associated photographs. The first and third author met with each participant, separate from the caregiver, to determine (a) whether they wished to modify the narratives, and (b) which photographs they felt best represented their stories. To maintain equivalence across participants, all narratives included two photographs and six written elements, which could be sentences or phrases, depending on the preference of the participant. Since the goal of this study was to examine how people interacted with a device during an initial exposure to the AAC system, this was done offline. That is, the final story was written out and the selected pictures laid next to the story for each participant to verify accuracy and make necessary edits to the phrasing, word selection, and/or photograph selection and order. Once the co-construction process was complete, the researchers uploaded two pictures into the VSD interface and programmed the agreed-upon text into the six text boxes (in relevant conditions) and the six speak buttons. On average, the text boxes included 12.4 words per text box (range: 5-21) with a Flesch-Kincaid Grade Level (Flesch, 1948) of 5.1 (range: 2.9-8.5). Because navigation was not a target of this investigation, the researchers designed the VSD interfaces to exclude all navigation options typically available in high-technology VSD systems.

Upon completion of the co-construction sessions, the researchers selected four narratives for each participant that included personally relevant photographs that most closely adhered to established guidelines regarding personally-relevant, high-context photographs (Dietz et al., 2006; McKelvey et al., 2007; 2010; Wallace, Dietz, Hux, \& Weissling, 2012). Specifically, the participants provided personally relevant images from their personal collections. During the co-construction process, the participants were encouraged to select high-context images, whenever possible. For example, if two pictures were available to represent a grandchild's birthday party, one high-context image (e.g., the group singing the Happy Birthday song to the child while she or he blew out the candles) and one low-context image (e.g., the group posing in front of the cake), the high-context image was selected for the narrative retell. From this pool, two narratives were randomly assigned to both the personally relevant and non-personally relevant narrative retell conditions. The researchers used the four remaining themes during the familiarization phase (see below).

For the non-personally relevant photographs, the researchers collected images from a variety of Internet search engines and adapted the procedures developed by McKelvey and her colleagues (2010) to confirm the contextual similarity between the personally relevant and non-personally relevant photographs. A panel of three judges rated whether the photographs conveyed the same concept using a scale in which $1=$ strongly disagree , $2=$ disagree , $3=$ neutral , $4=$ agree , and $5=$ strongly agree). To be used in the study, the average rating had to be 3 or higher $(M=3.9$, range: 3.6-4.6). For this study, the terms non-personally relevant and personally relevant refer only to the photographs, not the narratives.

\section{Procedures}

The participants completed two aphasia-testing sessions separately from the experimental sessions. All of the sessions occurred in a quiet conference room at either the University of Cincinnati or a local rehabilitation hospital. All participants were offered breaks after each retell and the option to continue the retells on another day. Due to fatigue, Brian opted to retell his stories across two sessions (i.e., two narratives per session), within a week of one another. Randy, Kelly, Phil, and Anne did not report or demonstrate fatigue and opted to retell all four narratives during a single session.

\section{Narrative Retell Sessions}

Prior to retelling the narratives, the first author introduced the people with aphasia and the communication partner and facilitated a 5-10 min "getting to know you" conversation, without the AAC device. This period allowed the people with aphasia and the communication partner to become comfortable with one another.

Familiarization with VSD. The third author familiarized the people with aphasia with the DynaVox VMax and VSD layouts using four narratives not employed during the retell session. At this time, the researcher also informed the people with aphasia that some pictures would be their personal photographs (while displaying a VSD with personally relevant photographs) and some pictures would not be their personal photographs (while displaying a VSD with non-personally relevant photographs). 
Additionally, the researcher specifically stated that sometimes the computer would have both text boxes and speak buttons (while displaying a VSD with these elements) and sometimes the computer would only show speak buttons (while displaying a VSD without text boxes). This information was provided using augmented input (Garrett \& Lasker, 2013; Wallace et al., 2012) via aphasia-friendly written instructions and gestures to key elements of the VSD during the explanation. Supplementary Appendix A outlines the researcher's activities during this session. The people with aphasia were encouraged to practice using the VSD with all four non-experimental narratives. Since the purpose of this study was to examine the initial VSD experience of people with aphasia, we did not require that they meet a predetermined criterion to move onto the retell session. Instead, the goal was to simply orient them to the interface.

Communication Partner Instructional Meeting. The first author met separately with the communication partner before each story retell to review a set of guidelines (see Supplementary Appendix A). In general, the guidelines required the communication partner to refrain from initiating the use of the VSD content; that is, she could not point to pictures, text, or use the speak buttons until the person with aphasia brought the item into the conversation. She was allowed to support the people with aphasia during their narrative retell through the use of conversation continuers such as, Tell me more about that and What else happened during your vacation? (Garrett \& Huth, 2002; McKelvey et al., 2007) and by discussing content using the VSD after the participants introduced the content (Griffith, Dietz, \& Weissling, 2014).

Retell Sessions. The first author reintroduced the people with aphasia and the communication partner. At this time, the researcher turned on the video cameras, set the DynaVox Vmax to the target story, and left the room. The communication partner initiated each narrative retell by stating, I understand you want to talk to me about (insert name of story). The retell session concluded when the people with aphasia indicated that they were done sharing their story and responded to the question, Is there anything else you want to tell me about this story? To reduce the adverse impact of order effects or any differences among the narratives; the presentation order of interface design was randomly assigned (see Supplementary Appendix B).

Social Validity Checks. Upon completion of each narrative retell, the third author asked the people with aphasia to respond to two written statements related to the perceived helpfulness of personally relevant and nonpersonally relevant photographs ("The pictures helped me tell the story") and the presence of text ("The written words helped/would have helped me tell the story").
They responded using a Likert-type scale with 5 points, with anchors described as $1=$ strongly disagree and $5=$ strongly agree. Additionally, follow-up probes allowed the researchers to learn more about the perceptions of the people with aphasia following each story retell experience (e.g., How did this story go? What did you think of these pictures?). From this brief dialogue, quotes regarding the participants' commentary on the various independent variables were extracted. Finally, following the last retell session, the communication partner was instructed to, Write down your thoughts and observations about your experiences interacting with the participant.

\section{Procedural Integrity}

A trained research assistant reviewed a random sample of $25 \%$ of the narrative retell sessions (i.e., one retell per participant) to document the extent to which the communication partner and the researcher adhered to the guidelines during the familiarization session (as outlined in Supplementary Appendix A). Procedural integrity was calculated using the following formula: number of times researcher/communication partner completed each task, divided by the total number of opportunities to complete each task $\times 100$. Analyses revealed that the communication partner followed the guidelines $99.25 \%$ of the time and the researcher followed the familiarization script $100 \%$ of the time.

\section{Data Analyses}

Transcription of Narrative Retells and Debriefings. A trained research assistant transcribed the video recordings verbatim. Transcriptions included all verbal and nonverbal communication modalities, including references to the VSD interface features, such as photographs, text, and the speech output of the DynaVox VMax. Written and drawn communications were also entered into the transcription. Two additional researchers verified the accuracy of all modalities; any discrepancy was resolved through discussion.

Dependent Measures. After transcription was complete, the first author and a trained research assistant coded transcriptions for six different types of expressive modality units, which included various subcategories: (a) spoken, (b) written, (c) drawn, (d) photograph, (e) text box, and (f) speak button. Since the narrative retell sessions were not limited to a specific time frame, the dependent measures described here are reported as percentages of total expressive modality units. Next, the researchers coded for trouble sources (i.e., communication breakdowns) and repairs. In addition, the repair trajectory, defined as the average number of expressive modality units required for a participant with aphasia to repair a breakdown, was also tabulated. It should be noted that, for the current study, the authors only coded one element of several possible types 
of trouble sources and repair sequences. Specifically, only trouble sources initiated by the communication partner were coded (Cunningham \& Ward, 2003; Schegloff, 2000). The analysis did not include instances of self-repair by the person with aphasia, which may have included self-corrections of word retrieval or other lexical difficulties. Finally, the length of time participants spent making off-topic commentary during the non-personally relevant retells was calculated (i.e., off-topic talk time), which included any reference to the idea that the photographs did not belong to them or questions about the location of their photographs. Supplementary Appendix C provides operational definitions for the dependent measures. Two excerpts of transcripts illustrating the dependent measures described here are located in Supplementary Appendix D.

To determine the perceived helpfulness of the different interface features, the participants' responses on the two Likert-type scales were tabulated, along with relevant commentary regarding their perception of each condition. Finally, the communication partner's perceived helpfulness of the interfaces during the retells was ascertained from her written reflection. The researchers reviewed this document and extracted comments that related to the interface features analyzed in this study.

Reliability. To ensure the reliability of the dependent measure coding, interrater reliability was calculated on $75 \%$ of the narrative retells for each dependent measure. Prior to coding each measure, two researchers jointly coded one retell $(25 \%)$ per participant for each target-dependent measure. This ensured that the raters applied the operational definitions in the same manner for each participant. After this meeting, each researcher independently coded the remaining transcripts. This procedure yielded an average agreement rate of $84 \%$ (range: $70-90 \%$ ) for expressive modality units; $80 \%$ (range: $60-100 \%$ ) for trouble sources; 93\% (range: $80-100 \%$ ) for repairs; and 85\% (range: 61-98\%) for off-topic talk time. All disagreements were resolved through discussion between the two raters.

\section{Results}

The following sections describe how five participants with chronic aphasia performed a narrative retell task using four different VSD layouts. For each participant, expressive modality units employed during each retell are reported as a percentage of total expressive modality units. Next, the percentage of expressive modality units that caused a trouble source, along with how the participants repaired trouble sources are summarized. Table 2 summarizes the expressive modality unit and trouble source/repair results. Following this section, off-topic talk time during the non-personally relevant conditions is reported as a percentage of the total narrative talk time and discussed in terms of the subsequent effect on trouble sources (see Table 3). Then, the participants' Likert scale data regarding the perceived helpfulness of the photographs is reviewed

Table 2. Frequency and (Percentage) of Expressive Modality Units and Trouble Source Behaviors Across Conditions.

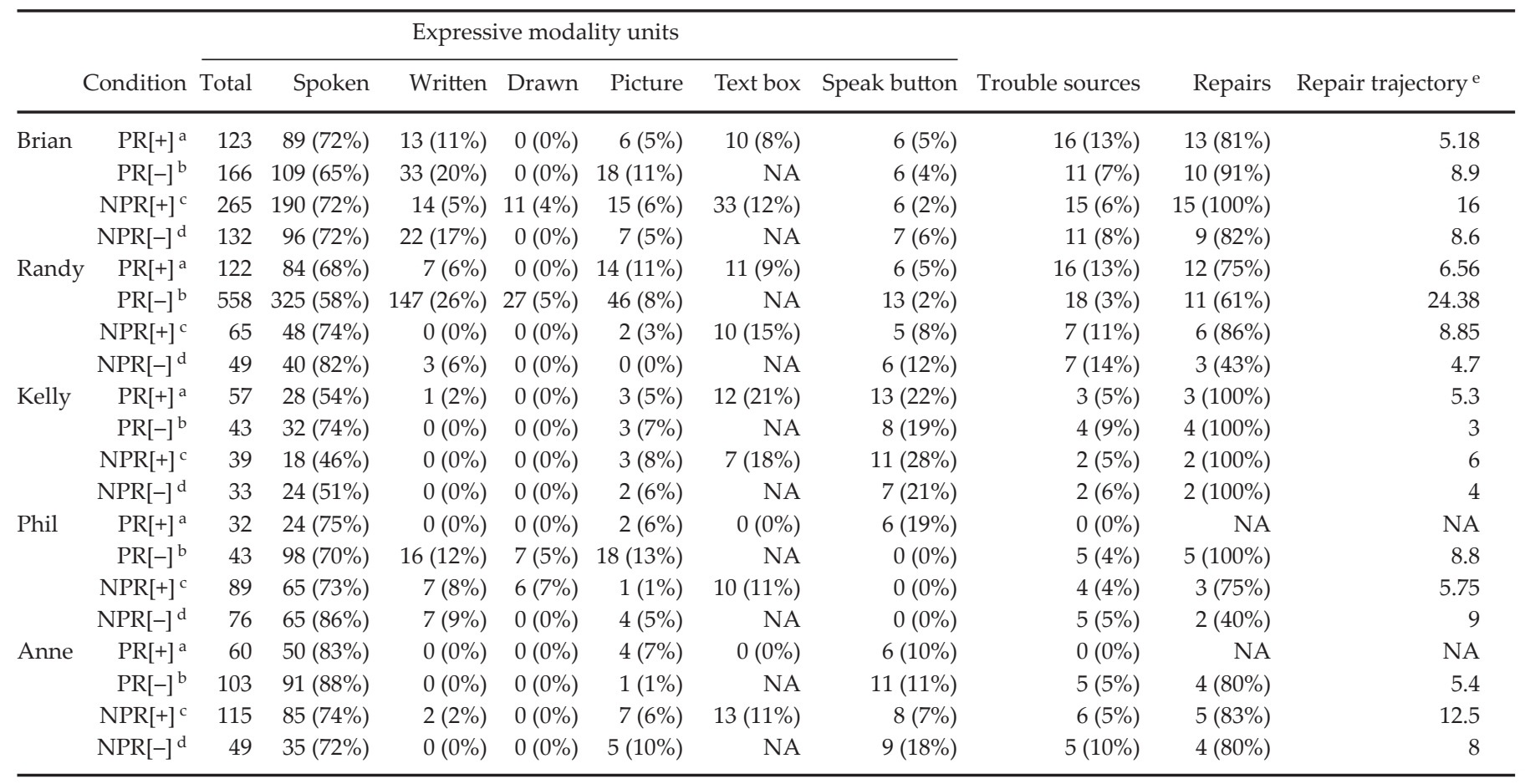

a) PR[+] personally relevant + text boxes, b) PR[-] personally relevant - text boxes; c) NPR[+] non-personally relevant + text boxes; d) NPR [-] nonpersonally relevant - text boxes; e) measured in average number of expressive modality units. The data are presented in raw number of instances (i.e., numbers outside of parentheses) and percentage of occurrence (i.e., numbers inside of parentheses). 
Table 3. Total Duration of Narrative Retells, Percentage of Off-Topic Talk Time, and Trouble Sources Due to Off-Topic Talk.

\begin{tabular}{|c|c|c|c|c|c|c|c|c|}
\hline \multirow[b]{2}{*}{ Participant } & \multirow{2}{*}{$\frac{\mathrm{PR}[+]^{\mathrm{a}}}{\begin{array}{c}\text { Total narrative } \\
\text { duration }\end{array}}$} & \multirow{2}{*}{$\frac{\mathrm{PR}[-]^{\mathrm{b}}}{\begin{array}{c}\text { Total narrative } \\
\text { duration }\end{array}}$} & \multicolumn{3}{|c|}{$\mathrm{NPR}[+]^{\mathrm{c}}$} & \multicolumn{3}{|c|}{$\mathrm{NPR}[-]^{\mathrm{d}}$} \\
\hline & & & $\begin{array}{l}\text { Total narrative } \\
\text { duration }\end{array}$ & $\begin{array}{l}\text { Off-topic } \\
\text { talk time }\end{array}$ & $\begin{array}{l}\text { Trouble sources } \\
\text { due to off-topic talk }\end{array}$ & $\begin{array}{c}\text { Total narrative } \\
\text { duration }\end{array}$ & $\begin{array}{l}\text { Off-topic } \\
\text { talk time }\end{array}$ & $\begin{array}{c}\text { Trouble sources } \\
\text { due to off-topic talk }\end{array}$ \\
\hline Randy & $6: 34$ & $24: 47$ & $4: 22$ & NA & NA & $3: 18$ & NA & NA \\
\hline Kelly & 4:09 & $2: 40$ & $4: 22$ & 0:49 (19\%) & $1(50 \%)$ & $2: 14$ & $0: 22(16 \%)$ & $2(100 \%)$ \\
\hline
\end{tabular}

a) PR[+] personally relevant + text boxes; b) PR[-] personally relevant - text boxes; c) NPR[+] non-personally relevant + text boxes; d) NPR [-] nonpersonally relevant - text boxes. Time is reported in minutes:seconds. The data are presented in raw number of instances (i.e., numbers outside of parentheses) and percentage of occurrence (i.e., numbers inside of parentheses).

(see Table 4) and relevant commentary regarding their perception of each condition is reported (see Supplementary Appendix E). Finally, the communication partner's observations regarding the helpfulness of the interface features are highlighted.

\section{Brian}

Expressive Modality Units. Across the four retells, Brian, used the spoken modality more often than other expressive modality units ( $M=70 \%$, range: $65-72 \%)$. Furthermore, in the no text box conditions, Brian appeared to use writing at higher rates $(M=19 \%$, range: $17-20 \%)$ than in the text box conditions ( $M=8 \%$, range: $5-11 \%)$. Brian referenced pictures at comparable rates across the four conditions, and no discernible patterns were observed for text box and speak button expressive modality units (see Table 2).

Trouble Sources and Repairs. Brian seemed to experience the highest rate of trouble sources during the PR[+] retell (13\% of total expressive modality units); however, this condition also yielded the shortest average repair trajectory at 5.18 expressive modality units. By comparison, the three remaining conditions produced lower levels of trouble sources $(M=7 \%$ of total expressive modality units, range: $6-8 \%)$, but longer average trajectories $(M=11.16 \%$ expressive modality units, range: $8.6-16 \%)$. Off-topic Talk Time. Brian spent a fair amount of time expressing that the non-personally relevant photographs did not belong to him ( $M=8 \%$ of retell duration, range: $7-9 \%$ ). This deviation from the narrative retell generated approximately $7 \%$ of the trouble sources that occurred during the NPR[+] retell; in contrast this effect was not observed during the NPR[-] retell (see Table 3).

Perceived Helpfulness of Photographs and Text. During the $\mathrm{PR}[+]$ retell, Brian rated the pictures as helpful (i.e., a score of 4 ) and the text boxes as very helpful (i.e., a score of 5). Following the PR[-] retell, Brian agreed that the pictures were helpful and that the presence of text would have been helpful (i.e., score of 4). Following both of the non-personally relevant retells, Brian indicated that the photographs were not helpful (i.e., score of 2). In contrast, he indicated that the text boxes were (or would have been) helpful during these retells (i.e., score of 4). Brian's scores are depicted in Table 4. In Supplementary Appendix E, Brian's interaction with the researcher following the NPR[-] condition shows that he wanted to be clear the researchers knew the pictures were not his.

\section{Randy}

Expressive Modality Units. Randy's most frequently used modality was spoken ( $M=71 \%$, range: $58-82 \%)$; compared to the retells with the personally relevant photos, he spoke at a higher frequency during retells with the

Table 4. Scores for Perceived Helpfulness of Pictures and Text Boxes.

\begin{tabular}{|c|c|c|c|c|c|c|c|c|}
\hline Participant & \multicolumn{2}{|c|}{$\operatorname{PR}[+]^{\mathrm{a}}$} & \multicolumn{2}{|c|}{$\operatorname{PR}[-]^{\mathrm{b}}$} & \multicolumn{2}{|c|}{$\mathrm{NPR}[+]^{\mathrm{c}}$} & \multicolumn{2}{|c|}{ NPR[- $]^{\mathrm{d}}$} \\
\hline Brian & 4 & 5 & 4 & 4 & 2 & 4 & 2 & 4 \\
\hline Randy & 5 & 4 & 4 & 4 & 4 & 5 & 3 & 4 \\
\hline Phil & 5 & 5 & 3 & 4 & 3 & 5 & 5 & 3 \\
\hline Anne & 5 & 5 & 5 & 5 & 5 & 5 & 1 & 4 \\
\hline
\end{tabular}

1 = strongly disagree ; 5 = strongly agree ; a) PR[+] personally relevant + text boxes; b) PR[-] personally relevant - text boxes; c) NPR[+] non-personally relevant + text boxes; d) NPR [-] non-personally relevant - text boxes. 
non-personally relevant photos. Randy used writing only $6 \%$ of the time during the PR $[+]$ and NPR $[-]$ retells, and not at all during the NPR $[+]$ retell. In contrast, writing comprised $26 \%$ of his total expressive modality units during the PR[-] narrative. Randy used pictures more frequently during the retells with personally relevant photographs $(M$ $=10 \%$, range: $8-11 \%$ ). In contrast, he referenced the pictures only a few times during the NPR [+] and not all during the NPR[-] retell. In regard to text box $(M=12 \%$, range : $9-15 \%)$ and speak button ( $M=7 \%$, range: $2-12 \%)$ references, Randy's usage was fairly similar during the personally relevant and non-personally relevant retells.

Trouble Sources and Repairs. Across the four retells, Randy experienced comparable levels of trouble sources $(M$ $=10 \%$ of expressive modality units, range: $3-14 \%$ ), with the lowest incidence of trouble sources occurring in the PR[-] condition. However, the PR[-] retell generated the second lowest repair rate $(61 \%)$ and the longest average repair trajectory (24.38 expressive modality units).

Off-topic Talk Time. Randy did not demonstrate off-topic commentary during any of the four retells.

Perceived Helpfulness of Photographs and Text. Generally speaking, Randy reported the photographs to be helpful or very helpful during the personally relevant retells (i.e., PR [+] score of 5, and PR[-] score of 4), and helpful during the NPR[+] condition (i.e., score of 4). In contrast, he rated the photographs in the NPR[-] as somewhat helpful (i.e., score of 3). Regarding the helpfulness of text, Randy indicated that the text was (or would have been) helpful (i.e., score of 4) during the PR[+], PR[-], and the NPR[-] retells and very helpful (i.e., score of 5) during the NPR[+] retell. The excerpt in Supplementary Appendix E from Randy following the NPR[+] condition reveals that he found the NPR pictures and text to be helpful when retelling his narrative.

\section{Kelly}

Expressive Modality Units. Of all participants, Kelly demonstrated the lowest percentage of spoken expressive modality units $(M=56 \%$, range: $46-74 \%)$; however, out of all of the participants, she did exhibit the most severe apraxia of speech. Her use of the spoken modality was the most pronounced in the PR[-] condition (74\%) and the least prevalent in the NPR[+] condition (46\%). Kelly wrote one time during the $\mathrm{PR}+]$ condition; otherwise she did not rely on writing or drawing during her retells. No discernible pattern regarding the use of pictures or text boxes as a communication modality was observed. Across the retells, Kelly used the speak buttons on average $23 \%$ of all expressive modality units (range: 19-28\%), which was the highest of all participants.
Trouble Sources and Repairs. Kelly demonstrated comparable percentages of trouble sources $(M=6 \%$, range: $5-9 \%)$ and successful repair rates $(M=100 \%)$ across all conditions. She exhibited longer average trajectories in both of the narrative retells with text boxes $(M=5.65$ expressive modality units; range: $5.3-6 \%$ ) when compared to the conditions with no text boxes $(M=3.5$ expressive modality units; range: $3-4 \%$ ). However, it should be noted that repairs were required infrequently; thus, these averages are based on a limited number of observations (see Table 2).

Off-topic Talk Time. During both non-personally relevant retells, Kelly spent a large percentage of time ensuring that the communication partner understood that the non-personally relevant pictures were not her personal photos $(M=18 \%$ of narrative retell duration, range: 16-19\%). The off-topic talk time caused $50 \%$ of trouble sources during the NPR[+] condition and $100 \%$ of the breakdowns during the NPR[-] retell (see Table 3). However, this difference is based on only a few total trouble sources during each retell (see Table 2).

Perceived Helpfulness of Photographs and Text. Kelly indicated that the photographs were very helpful (i.e., score of 5) during both personally relevant retells. Similarly, she reported that the text boxes were (or would have been) very helpful, or helpful, during the all four retells (scores were PR $[+]=5, \operatorname{PR}[-]=4, \mathrm{NPR}[+]=5$, and NPR $[-]=5$ ). In contrast, Kelly did not find the photographs helpful during the non-personally relevant retells (i.e., NPR $[+]=$ score of 2 and NPR[-] = score of 3) (see Table 4). During the post-narrative retell interview, Kelly reinforced the importance of the presence of the text boxes during her retells (see Supplementary Appendix E).

\section{Phil}

Expressive Modality Units. Overall, Phil relied primarily on the spoken modality to share his narratives $(M=$ $76 \%$, range: $70-86 \%$ ). Writing comprised an average of $7 \%$ (range: $0-12 \%$ ) of all modality units, which were only used during narrative retells where trouble sources occurred (i.e., PR[-], NPR[+], and NPR[-]); no writing was noted during the $\mathrm{PR}[+]$ condition. Phil referenced pictures most frequently during the PR[-] condition (13\%); and only a few times in the PR[+], NPR[+], and NPR[-]conditions. In regard to text use, Phil did not reference the text during the PR $[+]$ retell; he only referenced the text boxes during the NPR $[+]$ retell $(11 \%)$. Phil only used the speak buttons in the PR $[+]$ condition (19\%). Table 2 depicts Phil's use of the various types of expressive modality units across the retell conditions. 
Trouble Sources and Repairs. The combination of personally relevant pictures and supporting text appeared to play a facilitative role for Phil; more specifically, in the PR[+] condition he did not experience a single communication breakdown. Phil exhibited a similar percentage of communication breakdowns across the remaining conditions $(M=$ $4 \%$ of total expressive modality units, range: $4-5 \%)$. There are differences in Phil's rate of successful repairs (PR[-] = $100 \%$, NPR $[+]=75 \%$, NPR $[-]=40 \%$ ); however, when the actual instances of repairs were examined, the rate of repairs are fairly comparable. This is especially true for the non-personally relevant conditions, where there was only a difference of one repair.

Off-topic Talk Time. Phil exhibited a small proportion of off-topic talk ( $M=3 \%$ of total talk time, range: $1-4 \%$ ) during the non-personally relevant conditions. His off-topic commentary produced, on average, $23 \%$ (range: $20-25 \%$ ) of his trouble sources in the non-personally relevant conditions (see Table 3).

Perceived Helpfulness of Photographs and Text. Phil rated the pictures and text during the PR[+] retell, (i.e., score of 5) as very helpful. Following the PR[-], Phil rated the pictures as somewhat helpful (i.e., score of 3 ) and reported that the presence of text would have been helpful (i.e., score of 4). After the NPR [+] retell, Phil indicated that the photographs were somewhat helpful (i.e., score of 3 ) and that text was very helpful (i.e., score of 5). In contrast, for the NPR[-] retell, Phil perceived the pictures as very helpful (i.e., score of 5) but was unsure whether the presence of text would have helped him retell the narrative (i.e., score of 3) (see Table 4). Phil's excerpt in Supplementary Appendix E highlights his preference for the PR $[+]$ interface.

\section{Anne}

Expressive Modality Units. Anne relied primarily on the spoken modality to share her narratives $(M=79 \%$, range: 72-88\%). Compared to the non-personally relevant retells, she spoke at a slightly higher frequency during the personally relevant retells. The use of writing or drawing did not emerge as a preferred modality of communication during the retells, as she used few written expressive modality units (i.e., $2 \%$ ) only during the NPR[+] condition. However, Anne demonstrated relatively severe right-sided hemiparesis and indicated that she preferred not to use her nondominant, left hand to write or draw. Anne referenced pictures at variable rates across the retells $(M=6 \%$; range: 1-10\%); however, many of Anne's comments were centered on the fact that the pictures were not hers (see off-topic talk time below). During the NPR [+] retell, Anne used the text to help her carry the communicative load (i.e., $11 \%$ ); in contrast, she did not use the text boxes during the PR[+] retell.
Anne used the speak buttons at variable rates during the retells $(M=12 \%$; range: $7-18 \%)$.

Trouble Sources and Repairs. Anne experienced no communication breakdowns during the PR[+] retell. Meanwhile, she exhibited comparable performance regarding frequency of trouble sources across the remaining conditions ( $M=5 \%$ of total expressive modality units; range: 5-10\%). Furthermore, her rate of successful repairs was equivalent across the remaining retells (i.e., repairs: $M=$ $81 \%$, range: $80-83 \%$ ). Anne's non-personally relevant retells yielded slightly longer average trajectories $(M=7.25$ expressive modality units, range: $8-12.5 \%$ ), when compared to the PR[-] retell (5.4 expressive modality units).

Off-topic Talk Time. Anne spent a significant amount of time expressing that the non-personally relevant photographs did not belong to her $(\mathrm{NPR}[+]=11 \%$ of narrative retell duration); this was exacerbated when text was not present (NPR $[-]=26 \%$ of narrative retell duration). The offtopic talk resulted in an average of $18 \%$ of trouble sources (range: 17-20\%) during the non-personally relevant retells. It should be noted that the actual occurrence of trouble sources due to off-topic talk was one per non-personally relevant story.

Perceived Helpfulness of Photographs and Text. Anne rated the pictures as very helpful (i.e., score of 5) during the PR [+], PR $[-]$, and NPR [+] retells. In contrast, Anne did not rate the pictures as helpful (i.e., score of 1 ) during the NPR[-] retell. Regarding the presence of text, she indicated that the text was (or would have been) very helpful when retelling her PR[+], PR[-], and NPR[+] narratives (i.e., scores of 5) and that it would have been helpful (i.e., score of 4) during the NPR[-] retell. Anne's transcription segment (see Supplementary Appendix E) illustrates her frustration with the photographs following the NPR[-] retell.

\section{Communication Partner: Perceived Helpfulness of Photo- graphs and Text}

A review of the communication partner's reflection revealed that she perceived the presence of text and the personally relevant photographs to support her comprehension during the retells. The presence of text emerged as a critical element in her perceived understanding of the accuracy of the narrative retells. This is evidenced by the following excerpt from her reflection: “... sometimes I understood everything the participants said, but when there were no text boxes, I wasn't sure if what they were saying was actually the story or not." She clarified later in her writing that she "... may have misunderstood what they meant since [she] didn't see what was written [when text was not present]." She also perceived the presence of the 
personally relevant photographs as critical during the retells: "... it made the story more like a conversation, [and] I got to see actual artifacts/ personal items." In reference to the personally relevant photographs, she commented that, "... they used the pictures to help explain the story."

\section{Discussion}

\section{Use of Expressive Modality Units across Interface Type}

Each participant demonstrated individual patterns of preference for the supported modalities (i.e., written, drawn, text box, photograph, speak buttons), which may have been driven by various individual differences, such as the presence and severity of limb apraxia and paresis, reading/writing challenges, as well as apraxia of speech. However, on average, all five participants utilized spoken expressive modality units more than any other modality during the narrative retells. While only preliminary, and certainly not conclusive, these data counter the idea that AAC may facilitate learned non-use (Pulvermuller \& Berthier, 2008). Proponents of the theory of learned nonuse believe that the use of compensatory techniques limit the ability of people with aphasia to use verbal expression to convey their ideas. The notion that AAC does not preclude the use of spoken language is promising; however, this study only offered a one-time snapshot of the participants ' performance. The ratio of spoken to augmented expressive modality units may change over time, with instruction (Garrett et al., 1989; Koul et al., 2005; McKelvey et al., 2007; Johnson, Hough, King, Vos, \& Jeffs, 2008) and/ or continued use of the AAC system (Dietz et al., 2006, 2011). The type of instruction may also dictate how people with aphasia learn to use the various modalities available to them. Specifically, it is important to understand how people with aphasia incorporate AAC into their repertoire and to understand what factors cause them to use AAC as a substitute instead of a supplement to their spoken language. Understanding these differences will guide the development of AAC interventions that serve to simultaneously restore language and support communication.

\section{Influence of Interface Type on Trouble Sources and Repairs}

Overall, the occurrence of trouble sources was relatively low, which could be due to the nature of the communication task, which may have been perceived as a type of "institutional discourse" (Lindsay \& Wilkinson, 1999, p. 306) in which the participants may have assumed that the communication partner would initiate all repairs and pursue clarification of information (Griffith et al., 2014). Specifically, a young adult with no prior experience interacting with people who have aphasia was asked to listen to five older adults recount their personal narratives. Out of respect, the communication partner may not have felt comfortable asking for clarification on all unclear points. One interesting finding did emerge; neither Anne nor Phil (both of whom had no prior high-technology AAC experience) demonstrated trouble sources during the PR[+] retell. Phil and Anne's performance in this condition suggests that personally relevant images may help facilitate faster learning of VSD-based AAC systems, especially when text boxes are included (Dietz et al., 2006; McKelvey et al., 2007). This is consistent with the literature describing the use of text to support the communication of people with aphasia using low-technology AAC systems (Garrett \& Beukelman, 1995; Garrett \& Huth, 2002). However, since this collective case study lacked experimental control, these data are descriptive and it is not possible to determine causal relationships between the independent variables (i.e., types of interfaces) and the participants ' communicative behaviors. Since there were only five participants in this collective case study and there was variation across the participants, it is not possible to determine if there are indeed generalizable patterns across people with aphasia. This is especially true since Randy, who also had no prior high-technology AAC experience, did not demonstrate this same pattern. Randy's more significant comprehension challenges and reduced self-awareness may have limited his ability to experience the full benefit of the PR $[+]$ interface. Furthermore, the two participants with prior high-technology AAC experience, Brian and Kelly, both experienced trouble sources during all four retell sessions. This may be due to a higher comfort level using devices to repair breakdowns when they attempt to communicate about an idea that may be challenging to communicate without AAC. Said differently, perhaps those with AAC experience challenge themselves to say more during interactions because they are confident they have strategies to repair breakdowns. Given the variable patterns regarding trouble sources and repairs, as well as the varying AAC experience amongst the participants, it is important to consider the individual strengths and deficit areas for each person with aphasia during the assessment process. Furthermore, it is important to consider the importance of providing instruction to facilitate successful integration of AAC into a person's communicative repertoire (Garrett et al., 1989; Purdy \& Dietz, 2010; Purdy \& Koch, 2006; Purdy \& VanDyke, 2011).

It is also imperative to consider how the researchers defined trouble sources when interpreting these findings. In the conversational analysis literature, trouble sources are typically labeled as other-initiation of repair or self-initiation of repair (Cunningham \& Ward, 2003; Schegloff, 2000). For the current study, the authors only coded instances of other-initiation of repair, wherein the communication partner treats a prior turn by the person with aphasia as a trouble source by initiating a repair sequence. These repair sequences began when the partner made a clarification statement such as, What? or So, you mean XYZ happened? (See Supplementary Appendix D). However, the 
person with aphasia can also initiate repairs. In this case, the repair often originates in the same turn as the trouble source. Given the frequent lexical challenges experienced during conversation, this type of repair sequence is very common during interactions for people with aphasia. As such, the results regarding the instances of trouble sources and repair rate can only be interpreted in terms of whether the communication partner required additional information to understand the intent of the person with aphasia. Additional analyses that include self-initiation of repair would reveal different patterns of trouble sources and repair sequences.

\section{Off-Topic Talk Time}

Another important finding was the time that the participants with aphasia spent generating off-topic commentary during the non-personally relevant retells, which caused at least some trouble sources for three of the five participants with aphasia (Brian, Kelly, and Anne). This result may be due to an artificial effect created as a result of having two different conditions, such as retelling narratives with personally relevant and non-personally relevant photos, consecutively during one session. In other words, it is feasible that the off-topic commentary may not have occurred if the narratives had been shared under typical conditions, outside of the study. On the other hand, the off-topic commentary and subsequent trouble sources may have occurred because the non-personally relevant materials created disorientation and frustration, similar to what people experience when using unfamiliar interfaces during computer learning tasks (Chen et al., 2006). There may be several reasons why off-topic commentary did not emerge as a pattern for either Randy or Phil. Randy was the only person with fluent aphasia and moderately impaired reading and listening comprehension; informal observations confirmed his comprehension challenges and reduced self-awareness. For example, he often did not notice when a listener failed to understand his intent, and continued talking despite apparent confusion on the listener's behalf. Perhaps, his reduced selfawareness limited his ability to discern that the non-personally relevant images were not his photographs. Phil, on the other hand, demonstrated the mildest overall aphasia severity and the highest levels of reading and listening comprehension. For these reasons, he may have had the ability to overcome any disorientation that the juxtaposition of non-personally relevant photographs with personalized text may have created for Brian, Kelly, and Anne. Although this collective case study does not provide empirical evidence to guide clinical practice, these findings suggest support for the notion that personally relevant materials may facilitate improved communicative-linguistic performance compared to non-personally relevant materials (Jones et al., 2007; McKelvey et al., 2010; Schuell, 1953; Wallace \& Canter, 1983).

\section{Perceived Helpfulness of Photographs and Text}

Overall, the participants agreed that the personally relevant photographs were helpful or very helpful during the personally relevant retells. Phil was the exception; he did not find the pictures as helpful when text was not present (i.e., PR[-]). Generally speaking, the participants did not find the photographs as helpful during the non-personally relevant retells; however, several participants did rate the photographs as helpful or very helpful. For Randy and Anne, perhaps the photographs during the NPR[+] retell were helpful because text was present to provide context about a known topic. For Phil, the opposite was true; the presence of text regarding a familiar topic alongside nonpersonally relevant photographs seemed to be disorienting. In fact, people commonly become disoriented during computer learning tasks that include unfamiliar information (Chen et al., 2006). However, in the NPR[-] condition, the absence of personalized text seemed to eliminate this confusion, since he rated the photographs as very helpful. Overwhelmingly, the participants indicated that the text was (or would have been) helpful or very helpful across all narrative retells. The single exception was Phil, who seemed unsure about whether text would have been helpful during the NPR[-] retell. In summary, the participants generally found the text to be helpful, or reported it would have been helpful in the no text box conditions; and they perceived the personally relevant photographs as more helpful than the non-personally relevant photographs. Although this study was not designed to make causal connections between the interface and communication behavior, perhaps the personally relevant photographs and text elicited stronger activation of the visual sketchpad and thus, episodic long-term memory (i.e., Baddeley, 2000). As a result, the people with aphasia may have experienced more efficient and effective allocation of attentional resources to communication and language during the interactions using VSDs that included personally relevant photographs and text. In return, this may have translated into a perception of increased helpfulness in the presence of personally relevant photographs and text.

When considering these findings, it is important to consider that the researchers introduced bias regarding the helpfulness of personally relevant interfaces when they told the participants ahead of time that some pictures would be theirs and some would not. There may also be an implied preference for people with aphasia to use their own pictures to communicate (McKelvey et al., 2010). As such, the enjoyment derived from interacting with their own pictures could have influenced the quality of the personally relevant narrative retells. It is also feasible that the participants ' ratings reflect the specific narrative topics in each condition, since each retell employed a different narrative. Although all of the narratives were personally relevant, some stories may have elicited stronger emotions or motivation than others. Randy offers a good example 
with his PR[-] retell, which was about his hobby and passion, visiting Civil War battle sites. Anecdotally, during this retell, he seemed more insistent that the communication partner understood his exact intention, which could have led him to spend a considerably larger proportion of time using written expressive modality units during this retell compared to the other retells. As such, the PR[-] retell was his longest - by about $20 \mathrm{~min}$ - and he had less success repairing trouble sources than during the PR[+] retell. The perception of the naïve communication partner substantiates the helpfulness of using personally relevant materials. She noted that the people with aphasia used the personally relevant photographs to help tell their stories, which made the interaction more natural. Clearly, these findings must be interpreted with caution; however, the findings do seem to support the recent history of successful reports regarding the use of personally relevant photographs in AAC systems for people who have aphasia (e.g., Dietz et al., 2006; McKelvey et al., 2007; 2010; Wallace \& Hux, 2013).

Strengthening the argument regarding the helpfulness of the text was the communication partner's reflection. In her writing, she indicated that the presence of text boxes allowed her to be more confident in her ability to understand the narratives; thus, the presence of text may help reveal the communicative competence of people with aphasia - an important goal in aphasia rehabilitation (Kagan, Black, \& Duchan, 2001). The inclusion of text may be especially helpful for communication partners who have little to no experience interacting with people with aphasia, as such was the case for the partner in this study. It is possible, however, that-since the retells occurred across several months - the communication partner developed a bias regarding the interface features that she found most helpful. An important factor to consider when interpreting the positive response to the helpfulness of text is the education levels and reading ability of the participants in this study. All participants reported at least some college and four of the five participants demonstrated relatively good reading comprehension, with scores above 80 (out of 100) on the RCBA-2 (LaPointe \& Horner, 1998). This may explain the observed and perceived helpfulness of the text for this particular group; however, other studies also suggest that written supports are helpful to those with severe aphasia (e.g., Dietz et al., 2006; Smith \& Garrett, 2005). In the current study, Randy, who demonstrated moderately-impaired comprehension deficits, also reported the presence of text as helpful or very helpful across conditions. Nonetheless, it is important to assess the utility of text boxes at an individual level, which may require a modification of the amount of text that is paired with the photographs. In addition, since the researchers conducted the social validity interviews, experimenter bias could have affected the participants' responses to the questions regarding the helpfulness of photographs and text.

\section{Limitations and Future Directions}

This paper reflects the findings of a collective case study of five people with aphasia. In addition to the lack of experimental control inherent when using a collective case study design, it was not possible to control for the confounding effects of using different narratives in each of the experimental conditions. Thus, the results may have been influenced not only by the interfaces used, but also by the narratives themselves. Nonetheless, the patterns summarized here may act as a springboard for well-designed and controlled experimental investigations regarding how interface design influences the communicative and linguistic performance of people with aphasia. Not all people with aphasia - even those from a seemingly homogenous group - benefit equally from various interface designs. Even the small sample from this study supports this notion. As such, a largescale study that includes a variety of people with aphasia and documents the severity of their deficits across all four language modalities as well as their cognitive functioning profile may help determine various subgroups of people with aphasia who respond well to AAC intervention. In turn, this would help refine AAC intervention and assessment protocols to include instruction specific to the needs of the people who do not respond. Furthermore, a systematic evaluation of the various layouts and organizational structures, including the comparison of communication behaviors during retells using VSDs and traditional grid displays, would help delineate for clinicians what specific features will need to be evaluated during the initial assessment.

In addition to examining the interface features, it is important that the role of instruction is also evaluated. Previous research suggests that VSDs facilitate quick and efficient learning of AAC systems across various communication tasks (Garrett, \& Fox, 2007; McKelvey et al., 2007; Wallace \& Hux, 2013). The current study afforded the people with aphasia only one opportunity to use the various VSD interfaces. In the future, researchers should study the impact of continued exposure to the interfaces as well as the impact of scaffolded instruction. In 1989, Light proposed four domains of communicative competence: operational (the ability to effectively use a system), linguistic (mastery of the symbol system), social (implementation of appropriate pragmatic skills), and strategic (the ability to use the most appropriate strategy during a breakdown). The majority of previous AAC instruction designed for people with aphasia involves instruction related to linguistic and operational competence (Beck \& Fritz, 1998; Bellaire et al., 1991; Hough \& Johnson, 2009; Koul et al., 2005; Johnson et al., 2008; Purdy \& Dietz, 2010). This type of instruction is necessitated if people with aphasia use gridbased, categorically organized layouts. However, this instructional approach often yields limited generalization to life activities outside of treatment. As such, instruction protocols should also teach people with aphasia skills 
required for strategic and social competence to empower them with the ability to successfully navigate the communication experience (Light, 1989; Purdy \& Dietz, 2010, Purdy \& Koch, 2006). It is also important to examine the relative length, intensity, and generalizability of instructional protocols across various interface designs (e.g., traditional grid-based versus VSD interfaces). People with aphasia may demonstrate more effective communication skills with less intensive training when they use interfaces that build upon their strengths (i.e., personalized VSDs). Moreover, people with aphasia may also demonstrate increased motivation to utilize personalized materials (McKelvey et al., 2010).

Recently, Light and McNaughton (2014) updated the definition of communication competence to reflect communication in the 21st century. Their discussion of the changing scope of communication is pertinent to the implementation of AAC in people who have aphasia. Twenty-five years ago, AAC focused primarily on face-toface interactions; today, many interactions occur via social media such as Facebook and Twitter. In fact, social media has created "new age" VSDs that have made it commonplace for people to use videos and pictures with captions to communicate about life events (Dietz, Ball, \& Griffith, 2011; Light \& McNaughton, 2014). Despite the advantage of such VSDs, social media also requires increased linguistic and operational competence to successfully communicate the various platforms; this increased burden may overwhelm people with aphasia. Dietz and her colleagues (2011) offered suggestions on how to facilitate communication via social media through the application of supported reading and writing techniques; however, empirical research regarding the successful use of various social media platforms is needed.

Another important area of exploration in AAC for people with aphasia is the idea that AAC does not facilitate learned non-use of spoken language. This is particularly important considering that AAC interventions may be delayed until a plateau in language restoration occurs (Weissling \& Prentice, 2010). In fact, this approach to aphasia rehabilitation may be the culprit in perpetuating the long-standing idea that $\mathrm{AAC}$ and language restoration are mutually exclusive approaches to rehabilitation for people with aphasia. In the current study, the people with aphasia all used the spoken modality considerably more than they used the AAC system or other available low-technology AAC supports. However, this does not necessarily translate into superior spoken expression that might be documented via discourse analyses that address changes in content and complexity - or even in cortical plasticity via functional magnetic resonance imaging. In order for AAC to be accepted into more traditional restorative aphasia rehabilitation paradigms, well-controlled experiments that examine AAC-induced language restoration and cortical plasticity are critical.

\section{Notes}

1. PalmTop ${ }^{\mathrm{TM}}$ is a handheld AAC device that was formerly available through Dynavox Mayer-Johnson, 2100 Wharton Street, Suite 400 Pittsburgh, PA. 15203. The device is no longer commercially available.

2. DynaVox ${ }^{\mathrm{TM}}$ is trademark of DynaVox Mayer-Johnson, 2100 Wharton Street, Suite 400 Pittsburgh, PA 15203.

3. Canon FS200 is a product of Canon ${ }^{\mathrm{TM}}$, One Canon Park, Melville, NY 11747.

Acknowledgments - The authors would like to thank Brittany Sileo Fehskens, Anna Reinstatler, Jenna Wolf, Katie Sheridan, and Mikel Williams for their contributions to this project. The authors extend their appreciation to Drs. Sarah Wallace and John McCarthy for their comments on earlier versions of this paper. Lastly the authors are grateful for the participants' time and effort; because of them we have a better understanding of how people with chronic aphasia utilize various features of hightechnology Visual Scenes Displays. The project described was supported by the University of Cincinnati (UC) University Research Council (URC) New Faculty Grant. The authors report no conflicts of interest. The authors alone are responsible for the content and writing of the paper. The content is solely the responsibility of the authors and does not necessarily represent the official views UC URC.

\section{References}

AAC-RERC (2011). Mobile devices and communication apps. Retrieved from http://aac-rerc.psu.edu/index.php/pages/show/id/46

Baddeley, A. (2000). The episodic buffer: A new component of working memory? Trends in Cognitive Sciences, 4 (11), 417-423.

Beck, A., \& Fritz, H. (1998). Can people with aphasia learn iconic codes? Augmentative and Alternative Communication, 14, 184-196.

Bellaire, K. J., Georges, J. B., \& Thompson, C. K. (1991). Establishing functional communication board use for nonverbal aphasia subjects. Clinical Aphasiology, 19, 219-227.

Chen, S. Y., Fan, J. P., \& Macredie, R. D. (2006). Navigation in hypermedia learning systems: Experts vs. novices. Computers in Human Behavior, 22, 251-266.

Cunningham, R., \& Ward, C. (2003). Evaluation of a training programme to facilitate conversation between people with aphasia and their partners. Aphasiology, 17, 687-707.

Dietz, A., Ball, A., \& Griffith, A. (2011). Reading and writing in the 21st century: Technological applications of supported reading comprehension and written expression. Topics in Stroke Rehabilitation, 18, 758-769.

Dietz, A., McKelvey, M., \& Beukelman, D. (2006). Visual scene display: New AAC interface for persons with aphasia. Perspectives on Augmentative and Alternative Communication, 15, 13-17.

Dietz, A., McKelvey, M., Schmerbach, M., Weissling, K., \& Hux, K. (2011). Compensation for severe, chronic aphasia using augmentative and alternative communication. In S. S. Chabon \& E. Cohn, eds., The communication disorders casebook: Learning by example (pp. 351360). Boston, MA: Allyn \& Bacon/Merrill.

Dietz, A., Quach, W., Lund, S., McKelvey, M. (2012). AAC assessment and clinical-decision making: The impact of experience. Augmentative and Alternative Communication, 28, 148-159. doi: 10.3109/07434618.2012.704521 
Dukhovny, E., \& Soto, G. (2013). Speech generating devices and modality of short-term word storage. Augmentative and Alternative Communication, 29, 246-258. doi:10.3109/0743461 8.2013.815799

Flesch, R. (1948). A new readability yardstick. Journal of Applied Psychology, 32, 221-233.

Garrett, K., \& Beukelman, D. R. (1995). Changes in interaction patterns of an individual with severe aphasia given three types of partner support. Clinical Aphasiology, 23, 237-251.

Garrett, K. L., Beukelman, D. R., \& Low-Morrow, D. A. (1989). A comprehensive augmentative communication system for an adult with Broca's aphasia. Augmentative and Alternative Communication, 5, 55-61.

Garrett, K. L., \& Huth, C. (2002). The impact of graphic contextual information and instruction on the conversational behaviors of a person with severe aphasia. Aphasiology, 16, 523-536.

Garrett, K. L., \& Lasker, J. P. (2013). Adults with severe aphasia and apraxia of speech. In D.R. Beukelman \& P. Mirenda. (Eds.), Augmentative and alternative communication: Supporting children and adults with complex communication needs (pp. 405-445). Baltimore, MD: Brookes Publishing.

Griffith, J., Dietz, A., \& Weissling, K. (2014). Supporting narrative retells for people with aphasia using AAC: Photographs or line drawings? Text or no text? American Journal of Speech-Language Pathology, 23, S213-224.

Hough, M., \& Johnson, R. K. (2009). Use of AAC to enhance linguistic communication skills in an adult with chronic severe aphasia. Aphasiology, 23, 965-975.

Hux, K., Buechter, M., Wallace, S., \& Weissling, K. (2010). Using visual scene displays to create a shared communication space for a person with aphasia. Aphasiology, 24, 643-660.

Johnson, R. K., Hough, M. S., King, K. A., Vos, P., \& Jeffs, T. (2008). Functional communication in individuals with chronic severe aphasia using augmentative communication. Augmentative $\mathcal{E}$ Alternative Communication, 24, 1-12.

Jones, D. K., Pierce, R. S., Mahoney, M., \& Smeach, K. (2007). Effect of familiar paragraph comprehension in aphasia. Aphasiology, 21, 1218-1229.

Kagan, A. L., Black, S. E., Duchan, J. F., Simmons-Mackie, N., \& Square, P. (2001). Training volunteers as conversation partners using Supported Conversation for Adults with aphasia (SCA): A controlled trial. Journal of Speech, Language, E Hearing Research, 44, 624-638.

Kertesz, A. (2006). Western Aphasia Battery-Revised (WAB-R). San Antonia, TX: Pearson.

Koul, R., Corwin, M., \& Hayes, S. (2005). Production of graphic symbol sentences by individuals with aphasia: Efficacy of a computerbased augmentative and alternative communication intervention. Brain and Language, 92, 58-77.

La Pointe, L., \& Horner, J. (1998). Reading Comprehension Battery for Aphasia. Austin, TX: PRO-ED.

Light, J. (1989). Toward a definition of communicative competence for individuals using augmentative and alternative communication systems. Augmentative and Alternative Communication, 5, 137-44.

Light, J., \& McNaughton, D. (2014). Communicative competence for individuals who require augmentative and alternative communication: A new definition for a new era of communication? Augmentative and Alternative Communication, 30, 1-18. doi: 10.3109/07434618.2014.885080

Lindsay, J., \& Wilkinson, R. W. (1999). Repair sequences in aphasic talk: A comparison of aphasic speech and language therapist and aphasic-spouse conversations. Aphasiology, 13, 305-325.

McKelvey, M., Dietz, A., Hux, K., Weissling, K., \& Beukelman, D. (2007). Performance of a person with chronic aphasia using a visual scene display prototype. Journal of Medical Speech Language Pathology, 15, 305-317.

McKelvey, M., Hux, K., Dietz, A., \& Beukelman, D. R. (2010). Impact of personal relevance and contextualization on comprehension by people with chronic aphasia. American Journal of Speech-Language Pathology, 19, 22-33.

McNaughton, D., \& Light, J. (2013). The iPad and mobile technology revolution: Benefits and challenges for individuals who require augmentative and alternative communication. Augmentative and Alternative Communication, 29, 107-116. doi: 10.3109/07434618.2013.784930

Pulvermuller, F., \& Berthier, M.L. (2008). Aphasia therapy on a neuroscience basis. Aphasiology, 22, 563-599.

Purdy, M., \& Dietz, A. (2010). Factors influencing AAC usage by individuals with aphasia. Perspectives in Augmentative and Alternative Communication, 19, 70-78.

Purdy, M., \& Koch, A. (2006). Executive function ability in persons with aphasia. Aphasiology, 16, 549-557,

Purdy, M., \& VanDyke, J. A. (2011). Multimodal communication training in aphasia: A pilot study. Journal of Medical Speech-Language Pathology, 19, 45-58.

Schegloff, (2000). When 'others' initiate repair. Applied Linguistics, 21, 205-243.

Schuell, H. (1953). Aphasic difficulties: Understanding spoken language. Neurology, 3, 176-184.

Smith, C. E., \& Garrett, K. L. (2005). Comprehension of contextual vs. decontextual written choices in severe aphasia. Poster presented at the annual American Speech-Language and Hearing Association convention, San Diego, CA.

Thistle, J. J., \& Wilkinson, K. M. (2013). Working memory demands of aided augmentative and alternative communication for individuals with developmental disabilities. Augmentative and Alternative Communication, 29, 235-245. doi: 10.3109/07434618.2013.815800

Wallace, G. L., \& Canter, G. J. (1985). Effects of personally relevant language materials on the performance of severely aphasic individuals. Journal of Speech and Hearing Disorders, 50, 385-390.

Wallace, S. E., Dietz, A., Hux, K., \& Weissling, K. (2012). Augmented input: The effect of visuographic supports on the auditory comprehension of people with chronic aphasia. Aphasiology, 26, 162-176.

Wallace, S. E., \& Hux, K. (2013). Effect of two layouts on high technology AAC navigation and content location by people with aphasia. Disability and Rehabilitation: Assistive Technology, 9, 173-182.

Wambaugh, J. \& Wright, S. (2007). Improved effects of word-retrieval treatments subsequent to addition of the orthographic form. Aphasiology, 21 (6/7/8), 632-642.

Weissling, K., \& Prentice, C. (2010). The timing of remediation and compensation rehabilitation programs for individuals with acquired brain injuries: Opening the conversation. Perspectives in AAC, 19, 87-96.

Wilkinson, K., \& Jagaroo, V. (2004). Contributions of principles of visual cognitive science to AAC system display design. Augmentative and Alternative Communication, 20, 123-136.

Wilkinson, K. M., Light, J., \& Drager, K. (2012). Considerations for the composition of visual scene displays: Potential contributions of information from visual and cognitive sciences. Augmentative and Alternative Communication, 28, 137-147. doi: 10.3109/07434618.2012.704522

Wright, H. H., Downey, R. A., Gravier, M., Love, T., \& Shapiro, L. P. (2007). Processing distinct linguistic information types in working memory in aphasia. Aphasiology 21, 802-813.

\section{Supplementary material follows.}


Supplementary material for Dietz A. et al. (2014). The Impact of Interface Design During an Initial High-Technology AAC Experience: A Collective Case Study of People with Aphasia. Augmentative and Alternative Communication 30, 314-328.

\begin{abstract}
Appendix A
Researcher Behaviors during Familiarization Session and Communication Partner Guidelines

Researcher behaviors

1. Place the aphasia friendly instructions in front of the person with aphasia to augment comprehension.

2. Use the following script to introduce the AAC device using the 4 narratives not assigned to the experimental retells.

3. You will tell four stories using a computer (point to the device).

4. Some pictures will be your pictures (pointing to personally relevant photographs).

5. Some pictures will not be your pictures (navigate to nonpersonally relevant story and point to images).

6. The computer may have sentences (pointing to text boxes) and speak buttons (pointing to speak button).

7. (Navigate to a story without text boxes) The computer may only have speak buttons (push 2 speak buttons to demonstrate).

8. Do you want to practice using the computer? (go through the pages once more). Say, Do you want to touch the pictures? The text boxes? The speak buttons?

9. When they seem to be done, ask, Are you ready to begin? Re-explain as necessary and bring in the communication partner when they indicate that they are ready.

Communication partner behaviors $^{\mathrm{a}}$

1. Begin the story with, I understand you want to tell me about (insert name of story).

2. Provide adequate pause-time after asking a question or making a statement, to allow the person with aphasia time to answer.

3. Ask unlimited open-ended questions such as, What did you do next? and Where were you? Try to avoid and/or limit yes/no questions.
\end{abstract}


4. Repeat questions and/or write down key concepts when the person with aphasia asks for clarification.

5. Verbally interpret comments and/or gestures and ask for confirmation of correctness. For example, Let me make sure this is what you meant...

6. Avoid use of vocabulary related to the topic on the device unless the person with aphasia said or referred to this content first (i.e., includes natural speech as well as information located in the text boxes, photographs, and speech generated by the device).

7. Employ conversation continuers to facilitate the conversation during silent periods. (i.e., Tell me more about And What else happened while ?)

Notes. ${ }^{\mathrm{a}}$ Adapted from: Garrett \& Huth, 2002; McKelvey et al., 2007; and Griffith, Dietz, \& Weissling, 2014.

Appendix B

Random Interface Presentation Order for Retells

\begin{tabular}{ccccc}
\hline Participant & Retell 1 & Retell 2 & Retell 3 & Retell 4 \\
\hline Brian & PR[+] & NPR[-] & PR[-] & NPR[+] \\
Randy & NPR[+] & PR[-] & NPR[-] & PR[+] \\
Kelly & NPR[+] & PR[-] & NPR[-] & PR [+] \\
Phil & PR[+] & NPR[-] & PR[+] & NPR [+] \\
Anne & PR $[+]$ & NPR[-] & PR[-] & NPR $[+]$
\end{tabular}

Note: $\mathrm{PR}[+]$ personally relevant photographs + text boxes, $\mathrm{PR}[-]$ personally relevant photographs - text boxes, NPR $[+]$ non-personally relevant photographs + text boxes, NPR [-] non-personally relevant photographs - text boxes. 


\section{Appendix C}

Operational Definitions of the Coded Dependent Measures

Dependent measures $^{a} \quad$ Operational definitions

1. Expressive modality unit A piece of information conveyed through various modalities, including: spoken, written, drawn, text boxes, pictures, and speak buttons.

a. Spoken expressive modality unit b. Written expressive modality unit

c. Drawn expressive modality unit
A thought combined under a single, coherent intonation contour; usually, but not always preceded by a pause. A coherent intonation contour contains a single thought or idea. A new spoken expressive modality unit begins after a pause greater than $2 \mathrm{~s}$. Stereotypical utterances are coded as separate spoken expressive modality units. Lastly, a pause lasting longer than $5 \mathrm{~s}$ constitutes a separate spoken expressive modality unit (adapted from Mentis \& Prutting, p. 583-595).

Occurs when the person with aphasia exhibits a pause of 2 s or more in spoken production while writing and/or points/refers to their written text. If a person writes while speaking, 1 spoken and 1 written expressive modality unit is coded on the same line (adapted from Cunningham \& Ward, 2003).

Occurs when the person with aphasia exhibits a pause of $2 \mathrm{~s}$ or more in spoken production while drawing and/or points/refers to their drawing. If a person draws while speaking, 1 spoken and 1 drawn expressive modality unit is coded on the same line (adapted from Cunningham \& Ward, 2003).

Occurs when the person with aphasia references words located in a text box. If the person demonstrates a text box expressive modality unit while talking, it occurs on the same line, non-meaningful references to the text boxes, which do not carry information and have no "intent", are not coded (i.e., random pointing to text) (adapted from Cunningham \& Ward, 2003).

Occurs when the person references a picture, or part of a picture. If the person demonstrates a picture expressive modality unit while talking, it occurs on the same line. 
f. Speak button expressive modality unit

2. Trouble source

a. Repaired trouble source

b. Trajectory

3. Total duration of retell

4. Off-topic commentary talk time
Non-meaningful references to the pictures, which do not carry information and have no "intent", are not coded (i.e., random pointing to a picture) (adapted from Cunningham \& Ward, 2003).

Occurs when the person activates a speak button. If the person demonstrates a speak button expressive modality unit while talking, it occurs on the same line. Nonmeaningful activations of the speak buttons are not coded (i.e., accidental activation of the speak button) (adapted from Cunningham \& Ward, 2003).

A lack of information provided by the person with aphasia that impeded the transition or flow of the interaction, which prompts the communication partner to request more information/clarification (adapted from Cunningham \& Ward, 2003; Schegloff, 2000).

The trouble source was successfully resolved/clarified (adapted from Cunningham \& Ward, 2003; Schegloff, 2000).

The average number of expressive modality units required for the people with aphasia to repair the breakdown (adapted from Cunningham \& Ward, 2003; Schegloff, 2000)

The start-time was subtracted from the end-time. The starttime was determined by the first expressive modality unit of the people with aphasia in each story. The end-time was calculated immediately after the last expressive modality unit of the people with aphasia in each story.

The amount of time spent trying to convey that the nonpersonally relevant images did not belong to the participant or the participant questioning why their personally relevant pictures were not programmed into the device. The start-time was determined by the first expressive modality unit of non-personally relevant talk. The end-time was calculated immediately after the last expressive modality unit of non-personally relevant talk. Typically, there are multiple episodes of off-topic talk time that must be added together to determine the total off-topic commentary talk time. 
Appendix D

Excerpts from Narrative Retell Transcripts

Example \#1: Excerpt from Phil's Retell using the Personally Relevant [+]: Illustration of Expressive Modality Units

Phil: "Three boats raced, the Canadian 1 and 2 and the stars and stripes." [Speak Button Expressive Modality Unit] "My boat, the Canadian 2 won the race by two yards." [Speak Button Expressive Modality Unit]

Phil: Hum mmhm. [Spoken Expressive Modality Unit]

Communication Partner: Wow, nice.

Phil: Mhhm. Huh. [Spoken Expressive Modality Unit]

Communication Partner: Did you have a good time?

Phil: Yes. [Spoken Expressive Modality Unit]

Communication Partner: Yeah.

Phil: Yes, got sun burnt. [Spoken Expressive Modality Unit]

Communication Partner: You got sunburnt?

Phil: Yes very sunburnt. [Spoken Expressive Modality Unit]

Example \#2: Excerpt from Anne's Retell using the Non-Personally Relevant [-] Interface: Illustration of Trouble Source, Repair, Trajectory and Off-Topic Commentary Talk Time Anne: [Begin Off-Topic Commentary Talk Time] No um [Spoken Expressive Modality Unit] CABIN BOAT [Photograph Expressive Modality Unit] [Initiation of Trouble Source]

Anne: Uh Missigan Missigan [Spoken Expressive Modality Unit] (waves hand in front of AAC device points to each photograph) [Photograph Expressive Modality Unit] No and no...No uh no [Spoken Expressive Modality Unit]

Communication Partner: The pictures?

Anne: Yes [Spoken Expressive Modality Unit]

Communication Partner: What about the pictures?

Anne: Um huh No uh, house and no boat. [Spoken Expressive Modality Unit]

Communication Partner: No house and no boat? Were you in Michigan?

Anne: Yes. Mmm but um ww [Spoken Expressive Modality Unit]

Communication Partner: But not there?

Anne: No [Spoken Expressive Modality Unit] [Repaired Trouble Source] [End Off-Topic Commentary Talk Time] [Trajectory $=9$ Expressive Modality Units]

Note: the various types of expressive modality units, trouble sources, repaired trouble sources, off-topic talk time are coded using [ ]. 
Appendix E

Excerpts from the Participants' Post-Narrative Retell Interviews

\begin{tabular}{|c|c|c|}
\hline $\begin{array}{l}\text { Person with } \\
\text { aphasia }\end{array}$ & & Excerpt \\
\hline \multirow[t]{8}{*}{ Brian } & Researcher: & $\begin{array}{l}\text { So this story right here...(navigates to the NPR[-] } \\
\text { interface) this was easy... }\end{array}$ \\
\hline & Brian: & Yes. \\
\hline & Researcher: & $\begin{array}{l}\text { It was pretty easy. Good. Okay. So, tell me about the } \\
\text { pictures. }\end{array}$ \\
\hline & Brian: & Who? No. \\
\hline & Researcher: & $\begin{array}{l}\text { Yeah the pictures. What would you say? Did they help } \\
\text { you this time? }\end{array}$ \\
\hline & Brian: & $\begin{array}{l}\text { Yes, yes, yes. Ehhh. Two um, pictures. (points to the } \\
\text { non-personally relevant pictures) Some, no pictures... }\end{array}$ \\
\hline & Researcher: & They're different. \\
\hline & Brian: & Yes, yes, I pictures no. \\
\hline \multirow[t]{14}{*}{ Randy } & Researcher: & $\begin{array}{l}\text { Now tell me about the pictures. The pictures helped me } \\
\text { tell the story. }\end{array}$ \\
\hline & Randy: & $\begin{array}{l}\text { This is helped, uh oh pictures uh ...(pointing to non- } \\
\text { personally relevant pictures) }\end{array}$ \\
\hline & Researcher: & So did these pictures help you tell your story? \\
\hline & Randy: & Yeah but this is this is not normal. \\
\hline & Researcher: & $\begin{array}{l}\text { Right they are different so would you disagree or } \\
\text { agree that these pictures helped you. }\end{array}$ \\
\hline & Randy: & $\begin{array}{l}\text { Oh helped okay uhh... (circling " } 4 \text { " i.e., agree on a } \\
\text { Likert scale) }\end{array}$ \\
\hline & Researcher: & $\begin{array}{l}\text { So you could say you disagree that they did not help or } \\
\text { agree that they did help. }\end{array}$ \\
\hline & Randy: & Yeah this is agree. \\
\hline & Researcher: & So they kinda helped. \\
\hline & Randy: & Okay. \\
\hline & Researcher: & $\begin{array}{l}\text { Now tell me about the written words. The written } \\
\text { words helped me tell the story. Would you disagree or } \\
\text { agree? }\end{array}$ \\
\hline & Randy: & (circling " 5 " i.e., strongly agree on a Likert scale) \\
\hline & Researcher: & So they helped a lot. \\
\hline & Randy: & Yep. \\
\hline \multirow[t]{3}{*}{ Kelly } & Researcher: & $\begin{array}{l}\text { The written words would have helped me tell the story. } \\
\text { Do you agree or disagree? }\end{array}$ \\
\hline & Kelly: & Fine, yeah. (pushing a speak button) \\
\hline & Researcher: & $\begin{array}{l}\text { Yeah so, if there were words here would it have helped } \\
\text { you?... }\end{array}$ \\
\hline
\end{tabular}


Kelly: Yeah.

Researcher: So that's what you're saying. It would have helped a

lot. Ok, it would have been better.

Kelly: $\quad Y e a h$.

Researcher: The written words would have helped me tell the story.

$\begin{array}{ll} & \text { Do you agree or disagree? } \\ \text { Kelly: } & \text { Fine, yeah. (pushing a speak button) }\end{array}$

Phil Researcher: So what did you like about this story?

Phil: $\quad$ This. (pointing to the text boxes)

Researcher: You liked having the words there?

Phil: $\quad$ Yes, yeah, yeah.

Researcher: Okay. And then the Alaska story you liked...(navigates to the PR[-]interface)

Phil : $\quad$ The pictures I liked the pictures. (pointing to the two pictures)

Researcher: You liked the pictures. So, there weren't words this time...

Phil : $\quad$ No but I liked the pictures. The text.

Researcher: So if this one had words it'd be easier? It'd be best? (pointing to the PR[-]interface)

Phil: $\quad$ Ok, yeah, yes.

Researcher: Ah, okay.

Anne Researcher: Was this easy?

Anne: I Ion't know. No boat and no cabin. (pointing to nonpersonally relevant pictures of a boat and a cabin)

Researcher: Yeah, the pictures are different this time, aren't they?

Anne: $\quad Y e s$, mhm. I don't know. (shaking head)

\section{References}

Cunningham, R., \& Ward, C. (2003). Evaluation of a training programme to facilitate conversation between people with aphasia and their partners. Aphasiology, 17(8), 687707.

Garrett, K. L., \& Huth, C. (2002). The impact of graphic contextual information and instruction on the conversational behaviors of a person with severe aphasia. Aphasiology, 16, 523536. 
Griffith, J., Dietz, A., \& Weissling, K. (2014). Supporting narrative retells for people with aphasia using AAC: Photographs or line drawings? Text or no text? American Journal of Speech-Language Pathology,23, S213-224.

McKelvey, M., Dietz, A., Hux, K., Weissling, K., \& Beukelman, D. (2007). Performance of a person with chronic aphasia using a visual scene display prototype. Journal of Medical Speech Language Pathology, 15, 305-317.

Mentis, M., \& Prutting, C. A. (1993). Analysis of topic as illustrated in a head-injured and a normal adult. Journal of Speech and Hearing Research, 34,583-595.

Schegloff, (2000). When 'others' initiate repair. Applied Linguistics, 21(2), 205-243. 